\title{
MASS-BALANCE GRADIENTS AND CLIMATIC CHANGE
}

\author{
By J. OeRlemans and N.C. HOOGENDOORN
}

(Institute of Meteorology and Oceanography, University of Utrecht,

3584 CC Utrecht, The Netherlands)

\begin{abstract}
It is generally assumed that the mass-balance gradient on glaciers is more or less conserved under climatic change. In studies of the dynamic response of glaciers to climatic change, one of the following assumptions is normally made: (i) the mass-balance perturbation is independent of altitude or (ii) the mass-balance profile does not change - it simply shifts up and down. Observational evidence for such an approach is not convincing; on some glaciers the inter-annual changes in mass balance seem to be independent of altitude, on others not at all. Moreover, it is questionable whether inter-annual variation can be "projected" on different climatic states.

To see what a physical approach might contribute, we developed an altitude-dependent mass-balance model. It is based on the energy balance of the ice/snow surface, where precipitation is included in a parameterized form and numerical integrations are done through an entire balance year (with a $30 \mathrm{~min}$ time step). Atmospheric temperature, snowfall, and atmospheric transmissivity for solar radiation are all dependent on altitude, so a mass-balance profile can be calculated. Slope and exposure of the ice/snow surface are taken into account (and the effects of these parameters studied). In general, the calculations were done for $100 \mathrm{~m}$ elevation intervals.

Climatological data from the Sonnblick Observatory (Austria; $3106 \mathrm{~m}$ a.s.1.) and from Vent (2000 m a.s.l.; Oetztal Alps, Austria) served as input for a number of runs. Simulation of the mass-balance profiles for Hinterseisferner (north-easterly exposure) and Kesselwandferner (southeasterly exposure) yields reasonable results. The larger balance gradient on Kesselwandferner is produced by the model, so exposure appears to be an important factor here.

Sensitivity of mass-balance profiles to shading effects, different slope, and exposure are systematically studied. Another section deals with the sensitivity to climatic change. Perturbations of air temperature, cloudiness, albedo, and precipitation are imposed to see their effects on the mass-balance profiles. The results clearly show that, in general, mass-balance perturbations depend strongly on altitude. They generally increase down-glacier, and are not always symmetric about the reference state.

For typical climatic conditions in the Alps, we found that a $1 \mathrm{~K}$ temperature change leads to a change in equilibrium-line altitude of $130 \mathrm{~m}$. Three factors contribute to this large value: turbulent heat flux, longwave radiation from the atmosphere, and fraction of precipitation falling as snow. Here, the albedo feed-back increases the sensitivity in a significant way.
\end{abstract}

\section{INTRODUCTION}

The distribution of glaciers over the globe directly reflects climate variability associated with latitude, altitude, continentality, and large-scale atmospheric regime. Many factors contribute to glacier mass balance, and some of them are really of a local nature. A general theory, capable of explaining the large differences in mass balance from place to place, is therefore difficult to construct. Still, linking changes in the degree of glacierization of a region to climatic change in fact requires such a theory.
So far, regression techniques have been widely used to relate mass balance to meteorological parameters (e.g. Martin, 1978; Günther and Widlewski, 1986; Letréguilly, 1988). This normally involves annual specific balance or equilibrium-line altitude, and summer temperature, annual precipitation, annual temperature, early summer precipitation, etc. Although significant correlations generally exist, particularly between specific balance and summer temperature, it is not clear that relations thus found can be used in studying climatic change. As the cause of the inter-annual variations is not known or not traced, one should be cautious in "projecting" inter-annual changes on different climatic states. Such a consideration leads to the point of view that models, based on well-established physical laws, are the best tool to study the sensitivity of glaciers to environmental changes.

Mass-balance gradients are of particular interest. In studies concerning the response of glaciers to climatic change, either one of the following assumptions is normally made: the mass-balance perturbation is independent of altitude (e.g. Lliboutry, 1974) or the mass-balance profile does not change - it simply shifts up and down.

In fact, there is not much theoretical or observational evidence supporting the general validity of such assumptions. On physical grounds, it should be expected that a massbalance gradient will change if environmental parameters change. In what way depends to a large extent on the local climatological conditions (i.e. on the reference state). Figure 1 shows two typical situations. Measured mass-balance profiles are plotted for Devon Ice Cap $(19$ years $)$ and Hintereisferner (20 years). For Hintereisferner, the assumption that annual mass-balance perturbations are independent of altitude seems to be reasonable, at least at first sight (Kuhn (1986) in fact has shown that, when comparing years with extreme positive and negative balances of Hintereisferner, the anomalies do depend on altitude). For Devon Ice Cap, on the other hand, a very strong correlation between annual balance and balance gradient seems to exist. Negative values of the net balance apparently must be due to larger ablation and thus occur with steeper gradients. Kuhn (1984) has compared altitude-dependence of massbalance anomalies for a number of glaciers. It appears that almost every pattern is possible. Some glaciers have the largest anomalies in the vicinity of the equilibrium line, others further up- or down-glacier. Here the local situation and the large-scale climatic conditions are both decisive.

As discussed for instance in Kuhn (1981) and Oerlemans (1989), various factors contribute to the gradient in annual balance. The most important are:

(1) Precipitation changes with altitude. Here the orographic influence is dominating, and snowdrift may also affect the gradient in a significant way, in particular in the upper part of an accumulation zone.

(2) Although the shortwave insolation does not depend strongly on altitude, the absorption does, because surface albedo decreases drastically when going down-glacier.

(3) Air temperature decreases with altitude, reducing the turbulent energy exchange as well as the incoming longwave radiation. Another consequence is that the fraction of precipitation falling as snow increases with altitude. 


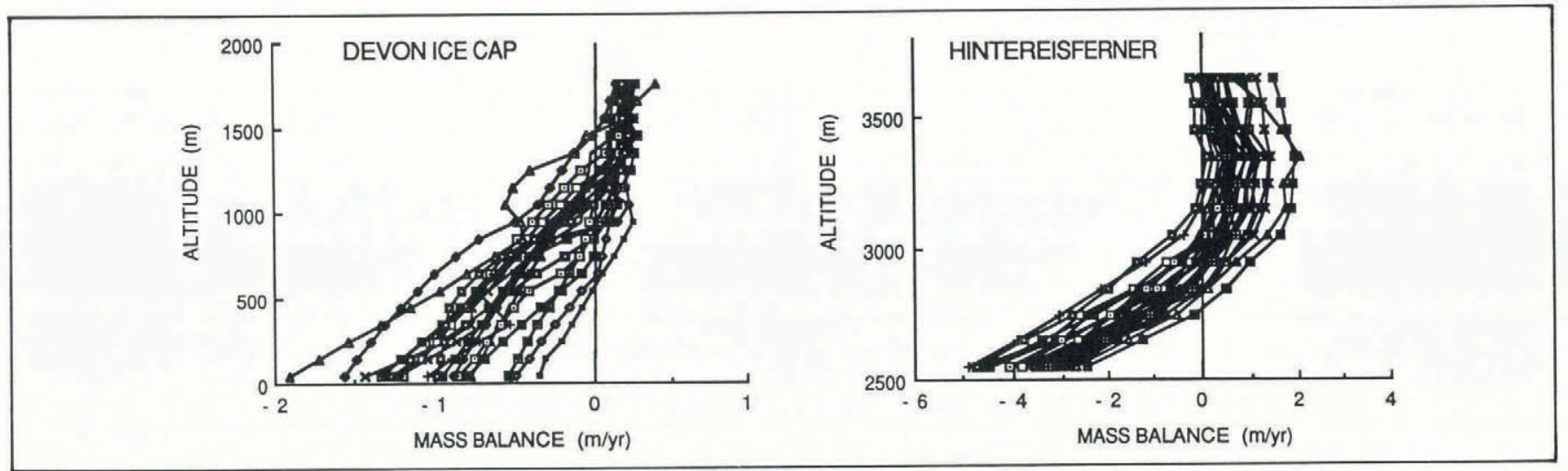

Fig. 1. Observed annual mass-balance profiles for Devon Ice Cap (lat. $75^{\circ} 25^{\prime} \mathrm{N}$., long. $83^{\circ} 15^{\prime} \mathrm{W}$.) and Hintereisferner (lat. $46^{\circ} 48^{\prime} \mathrm{N}$., long. 10 $46^{\prime}$ E.). Data from Kasser $(1967,1973)$ and Haeberli (1985).

(4) The degree of snow and ice cover normally decreases down-glacier. This induces increasing transport of heat from ice-free regions to the glacier. In particular, when the snout of a glacier is narrow, a significant increase in the melting rate may result.

In this study, results from a mass-balance model are presented that may contribute to the discussion on balance gradients and climatic change. In this model, at least some of the factors listed above are dealt with. An energy-balance model, including an annual and daily cycle, is formulated as "general" as possible. This involves altitude-dependent parameterizations of the radiative fluxes, taking into account slope and aspect of the surface, and using a formulation for the albedo that provides a time-dependent description of the fresh snow/old snow/firn/ice/dirty ice transition when appropriate. The model is a modified version of the one developed in Greuell and Oerlemans (1986; GO in the following), and we refer to this paper for a more extensive discussion on the parameterization of the radiative fluxes, and a diagnosis of the daily cycle in the components of the energy budget. The energy balance of a glacier surface has received considerable attention in the literature anyway, so here we will concentrate on the simulation of the annual mass balance.

One modification has been made to the model referred to above: the calculation of the temperature and density profile in the upper part of the glacier has been taken out, because it requires a large amount of computer time and was not considered essential for the present sensitivity study. However, we realize that in particular situations (very little melt, large daily and annual cycle) heat and water storage can be important, even for the annual balance.

The primary goal of this paper is to discuss sensitivity experiments performed with the "mass-balance model", and to demonstrate that it may be a very useful tool in the study of climate-glacier relationships. The dependence of mass-balance gradient on factors like air temperature, albedo, exposure, and surface slope will be the main interest.

\section{THE MASS-BALANCE MODEL}

The basic equation employed here is:

$$
M=\int_{\text {year }}[\min (0 ;-B / L)+P] \mathrm{d} t .
$$

Here $M$ is the annual mass balance, $L$ is the latent heat of melt, $B$ is the energy balance at the surface, and $P$ is the solid precipitation. So, melting occurs as soon as the energy balance becomes positive. It is further assumed that all melt water runs off; snowdrift and water transport in the firn aquifer are not considered. The components of $B$ are shortwave (solar) radiation, longwave (terrestrial) radiation, and turbulent energy fluxes (moisture and enthalpy).

\section{Solar radiation}

Since the purpose of this study is to consider the effects of slope and aspect, special attention was given to the calculation of the solar radiation. The model requires the solar flux at any time of the day, at any latitude, for a surface with any possible orientation. The amount $S$ of solar energy absorbed at a surface (which may be tilted), per unit area, is written

$$
\begin{array}{ll}
S=Q F(\psi, a, \gamma, d)(1-\alpha) T_{\mathrm{r}} T_{\mathrm{g}} T_{\mathrm{w}} T_{\mathrm{a}} T_{\mathrm{n}} & (e \geqslant 0), \\
S=0 & (e<0) .
\end{array}
$$

$T_{\mathrm{r}}, T_{\mathrm{g}}, T_{w}$, and $T_{\mathrm{a}}$ are the transmission coefficients for Rayleigh scattering, absorption by permanent gases, absorption by water vapour, scattering and absorption by aerosols, respectively. $T_{\mathrm{n}}$ represents the effects of clouds. The solar elevation is denoted by $e . Q$ is the solar constant, which varies slightly through the year and $\alpha$ is the surface albedo. The function $F$ describes the geometric effects. It depends on solar elevation $\psi$, azimuth $a$, surface slope $\gamma$, and aspect $d$. A further discussion on $F(\psi, a, \gamma, d)$ will not be given here, because this involves standard theory only. A derivation of the equations can for instance be found in Sellers (1965) or Walraven (1978).

The transmission coefficients are the same as those described in GO, including the dependence on solar zenith angle, surface elevation, and cloudiness. Here we just show a figure to illustrate the importance of the various effects (Fig. 2). The transmissivities are shown in dependence of surface elevation, for a solar zenith angle of $60^{\circ} . T_{\mathrm{w}}$ increases strongly when going up, which is related to the

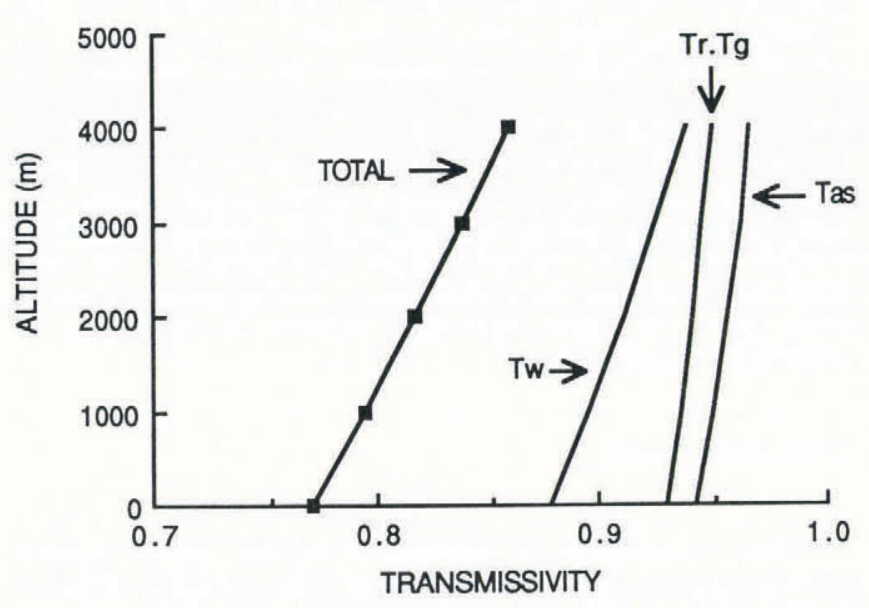

Fig. 2. Atmospheric transmissivities as used in the parameterization of solar radiation, shown for a solar elevation of $60^{\circ}$. The subscripts refer to water vapour $(w)$, Rayleigh scattering $(r)$, absorption by permanent gases $(g)$, and aerosol (as). 
assumption of constant relative humidity, i.e. rapidly decreasing optical mass. Referring to the total transmissivity, the variation with elevation is certainly significant. For a clear sky, the amount of solar radiation impinging on a horizontal surface at $4000 \mathrm{~m}$ is almost $10 \%$ larger than on a surface at sea-level. Of course, this represents average conditions.

The effect of clouds is also treated in the same way as described in GO. We will not repeat the formulation here. For total cloud cover, the effective transmissivity is 0.35 for an elevation of $2000 \mathrm{~m}$, and 0.45 for an elevation of $3000 \mathrm{~m}$. For a further discussion, see for instance Meyers and Dale (1983).

The critical parameter in Equation (2) is the surface albedo. It varies from 0.9 for fresh snow to as small as 0.15 for dirty ice. To deal with this, a time-dependent calculation of the surface albedo has to be performed. The formulation used here reads:

$$
\begin{array}{ll}
\mathrm{d} \alpha / \mathrm{d} t=\left(\alpha_{0}-\alpha\right) / t_{0} & \text { for snow, } \\
\mathrm{d} \alpha / \mathrm{d} t=\left(\alpha_{1}-\alpha\right) / t_{1} & \text { for ice. }
\end{array}
$$

Whenever snowfall occurs $\alpha$ is set to 0.85 . If bare ice appears at the surface for the first time in the ablation season, $\alpha$ is set to 0.45 . The final albedo for snow $\left(\alpha_{0}\right)$ is set to 0.45 , for ice $\left(\alpha_{1}\right)$ to 0.18 . The $e$-folding time-scales $t_{0}$ and $t_{1}$ differ widely. Here we used 10 and $30 \mathrm{~d}$, respectively. This parametrization of the albedo is admittedly very schematic, but it matches in broad line the results from the studies of Dirmhirn and Trojer (1955), Scheibbner and Mahringer (1968), Dirmhirn and Eaton (1975), and Wagner (1979). It should be stressed that there is no prescribed altitude-dependence of the albedo, nor of the asymptotic values $\alpha_{0}, \alpha_{1}$ and the time-scales $t_{0}, t_{1}$. The variation of surface albedo along the glacier is thus internally generated.

\section{Longwave radiation}

The longwave radiation is written as:

$$
R=\varepsilon \sigma \Theta_{\mathrm{S}}^{4}+\varepsilon_{\mathrm{a}} \sigma \Theta_{\mathrm{a}}^{4}+n v \Theta_{\mathrm{cl}}^{4} .
$$

Here $\Theta_{\mathrm{S}}, \Theta_{\mathrm{a}}$, and $\Theta_{\mathrm{cl}}$ are temperature of the surface, of the air just above the surface (screen height), and of the cloud base, respectively. Cloud emissivity is indicated by $v$, and surface emissivity $\varepsilon$ can be set to 1 . The atmospheric emissivity $\varepsilon_{\mathrm{a}}$ applies to the entire spectrum and is for clear-sky conditions. The dependence on vapour pressure and temperature is included in approximate form. For the various formulations and (empirical) constants, see GO.

\section{Turbulent fluxes}

The turbulent fluxes are calculated from the well-known bulk equations for turbulent exchange, based on the mixing-length theory (e.g. Priestley, 1959; see Kuhn (1979) for a discussion concerning the turbulent fluxes over a glacier surface). The application of this method to conditions above a melting glacier surface certainly has problems: the stratification is usually very pronounced and the generation of turbulence is entirely mechanical. Using stability functions (derived for slightly stable conditions) definitely leads to fluxes that are too small. Also, the wind velocity poses a problem. Just above the surface of larger glaciers, katabatic flows develop that generate turbulence. Using, for instance, wind data from a nearby weather station would in most cases underestimate the turbulent exchange. Here the problems are circumvented by simply using the relations ( $q$ is specific humidity):

$$
\begin{gathered}
F_{\mathrm{H}}=C_{\mathrm{H}}\left(\Theta_{\mathrm{S}}-\Theta_{\mathrm{a}}\right), \\
F_{\mathrm{L}}=C_{\mathrm{L}}\left(q_{\mathrm{S}}-q_{\mathrm{a}}\right) .
\end{gathered}
$$

Air density and surface wind velocity are absorbed in the exchange coefficients. In the present study this dependence was disregarded (note that, in reality, the decrease of density with elevation will be counteracted by increasing mean wind velocity). In all calculations reported here we used $C_{\mathrm{H}}=10 \mathrm{~W} /\left(\mathrm{m}^{2} \mathrm{~K}\right)$ and $C_{\mathrm{L}}=L C_{\mathrm{H}} / c_{\mathrm{p}}$, where $c_{\mathrm{p}}$ is the specific heat for dry air. These values for the exchange coefficients are in the middle of the range of what is mostly found in the literature.

\section{Precipitation}

In the present model, the monthly amount of precipitation serves as input. Precipitation occurs on three consecutive days out of five. So in a month there are roughly six "precipitation events", and the precipitation rate is constant through the day. When air temperature is below $2 \mathrm{~K}$, the precipitation falls as snow. In the case of rain all the water runs off, so there is no contribution to the mass balance.

In the experiments for a fictitious glacier with the Sonnblick climatological data, precipitation was assumed to be independent of altitude. So the change of accumulation is entirely determined by the fraction that falls as snow. In the simulation of the mass-balance profiles of Hintereisferner and Kesselwandferner, a correction could be made on the basis of simultaneous measurements at Vent and on Hintereisferner. The relation used reads (Greuell, unpublished):

$$
P(z)=P_{\text {Vent }}\left\{1+\left(z-Z_{\text {Vent }}\right) / 10000\right\} .
$$

Here $P(z)$ is monthly precipitation, and $z$ is altitude. So the difference in precipitation between Vent $(2000 \mathrm{~m})$ and the upper accumulation area of Hinterseisferner $(\approx 3500 \mathrm{~m})$ is about $15 \%$ (this increase may be too small according to Kuhn (personal communication)).

\section{RESULTS OBTAINED WITH CLIMATIC DATA FROM SONNBLICK AND VENT}

In this paper we will not discuss the simulation of the daily cycle, since this has been done in many other studies (also in GO for Sonnblick). Instead, we concentrate on the annual mass budget, its dependence on altitude, and its sensitivity to changes in the climatic parameters.

As a reference experiment, a run was made with climatological data from the Sonnblick station $(3106 \mathrm{~m}$, Austrian Alps). Monthly values (long-term mean) of air temperature, humidity, cloudiness, daily temperature range, and precipitation were used to "force" the mass-balance model. The mass balance has been calculated for a number of surface elevations, adjusting air temperature by using a constant atmospheric lapse rate of $6.5 \mathrm{~K} / 1000 \mathrm{~m}$. The resulting mass-balance profile (for a fictitious glacier) is shown in Figure 3. It certainly has the characteristics typical of glaciers in the Alps, but there is no possibility of straightforward validation. This experiment was done, however, since the data set from Sonnblick is considered to be one of the best from a high-altitude observatory.

The contribution of radiation to the total ablation appeared to be quite large. Although it is generally assumed

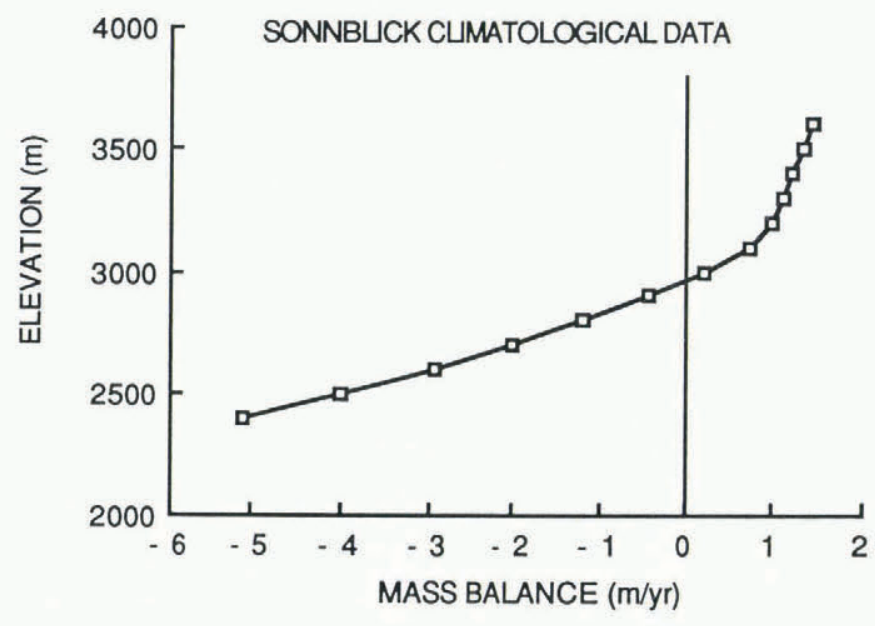

Fig. 3. Mass balance (water equivalent) calculated for a fictitious glacier at Sonnblick meteorological observatory ( $3106 \mathrm{~m} ;$ Austria). Temperature has been extrapolated using a $6.5 \mathrm{~K} / \mathrm{km}$ lapse rate. 
that the relative contribution of the turbulent heat fluxes decreases with altitude, this was not the case in our Sonnblick experiment. In fact, at almost all altitudes with significant ablation, the contribution was about one-third of that by radiation. An inspection of the energy-balance components for a mid-summer day (Table I) reveals that this is associated with the strong increase of surface albedo

TABLE I. ALTITUDINAL GRADIENTS IN THE COMPONENTS OF THE ENERGY BALANCE ON 16 JULY, AT NOON (SONNBLICK CLIMATOLOGICAL DATA). THE GRADIENTS ARE MEAN VALUES FOR THE 2500-3000 m INTERVAL

\section{Component}

Sensible heat flux

Longwave radiation

Insolation (horizontal surface)

Absorbed shortwave radiation
Latent heat flux

Gradient

$\mathrm{W} / \mathrm{m}^{2}$ per $100 \mathrm{~m}$

-0.68
-6.92
-4.45
+4.60
-42.35

with altitude, as represented in the model. Consequently, the increase in absorption of solar energy when going downward is of the same order of magnitude as the increase in the turbulent energy fluxes. We believe that this is a realistic feature on glaciers with a low albedo on the tongue. An analysis of energy-balance measurements on the tongue of Hintereisferner revealed that, due to a low surface albedo, $90 \%$ of the ablation energy came from radiation (personal communication from W. Greuell). It should be added, however, that this was for a $10 \mathrm{~d}$ period only with generally sunny weather.

In a second experiment, climatological data from Vent (Oetztal Alps, Austria; data obtained from the University of Innsbruck) were used in an attempt to simulate the massbalance profiles of Hintereisferner and Kesselwandferner. These glaciers were selected because long-term mass-balance measurements are available. Also, the glaciers are located very close to each other but have a different exposure (Hintereisferner: north-east; Kesselwandferner: south-east). A comparison of calculated and observed mass-balance profiles therefore appears to be an interesting test for the mass-balance model. Extrapolation of data from Vent to the actual locations of the glaciers may introduce errors, in particular concerning precipitation. Still, a better data set for the present purpose is difficult to find. For an extensive discussion on the relation between the mass balance of Hintereisferner and meteorological parameters observed at Vent, see Greuell (unpublished). The data used in this particular experiment are given in Table II.

In the calculation performed here, temperature was again obtained by using a constant atmospheric lapse rate, cloudiness as observed in Vent was not adjusted, but precipitation was corrected according to Equation (7). The geometric factors like aspect and slope of the ice surface and shading by nearby mountains were taken into account, as they are expected to be important.

Again, the computations were carried out for $100 \mathrm{~m}$ intervals (elevation), and the resulting mass-balance profiles for Hintereisferner and Kesselwandferner are shown in Figure 4. The long-term mean values from observations are also plotted. For Hintereisferner, this covers a period of 26 years, and for Kesselwandferner 14 years. First of all, there is a large discrepancy between calculated and observed balance in the upper parts of the accumulation zones. This is not at all surprising, since snowdrift, which is assumed to be the main reason for decreasing accumulation with altitude on those glaciers, is not treated in the model. At elevations around $3200 \mathrm{~m}$, the calculated mass balance matches the observations well, but this is a direct consequence of prescribing the precipitation. When looking further down, the calculated mass-balance gradient for Kesselwandferner is too large. For Hintereisferner it is correct, but the value of the calculated balance is systematically too low.

In spite of these shortcomings, the model is able to reproduce the major part of the difference between Kesselwandferner and Hintereisferner, which, in the present calculation, is entirely due to differences in exposure, surface slope, and shading. This is illustrated by the following numbers. The r.m.s. error for the simulation of the Hintereisferner mass balance is $0.60 \mathrm{~m} /$ year, and for Kesselwandferner it is $0.79 \mathrm{~m} /$ year. The r.m.s. difference between observed profiles for Hintereisferner and Kesselwandferner is $1.67 \mathrm{~m} /$ year, i.e. significantly larger. It is likely that the errors in the simulation are associated with inhomogeneities in cloudiness, albedo, air temperature, and precipitation. Some further tuning could be done to reduce the r.m.s. errors, but this was not considered to be a very useful exercise.

To get a further feeling for the performance of the model, some calculations were done for other slopes and exposures, and for various degrees of shading. Here, the Sonnblick data were used again, and the profile of Figure 3 then serves as a reference. Some results are presented in Figure 5. Mass-balance profiles are shown for a surface slope of $20^{\circ}$, for southerly and northerly exposure, and compared to the reference profile. Apparently, the simulated balance gradient is much larger on the southerly slope. Below the equilibrium line, it is twice the value obtained for a northerly slope! This is due to the difference in insolation, of course, enhanced by the albedo feed-back (the mean albedo is lower when melting conditions last longer). The right-hand panel gives an impression of how the mass balance at a specific elevation $(2600 \mathrm{~m}$ in this case) depends on exposure. Runs were done for every $45^{\circ}$, again for a slope of $20^{\circ}$. It is interesting to see a slight asymmetry around the north-south line $\left(180^{\circ}\right)$, which is related to a small daily cycle in the surface albedo. This daily cycle is only present in long-term mean conditions, since the variation on a particular day depends very much on the

TABLE II. CLIMATOLOGICAL DATA FOR VENT $(2000 \mathrm{~m})$ AS USED IN THE SIMULATION OF THE MASS-BALANCE PROFILES OF HINTEREISFERNER AND KESSELWANDFERNER. (KINDLY PROVIDED BY M. KUHN, UNIVERSITY OF INNSBRUCK.)

\begin{tabular}{|c|c|c|c|c|c|}
\hline Month & Daily temperature & Daily temperature range & Vapour pressure & Precipitation & Cloudiness \\
\hline & ${ }^{\circ} \mathrm{C}$ & ${ }^{\circ} \mathrm{C}$ & mbar & $\mathrm{mm}$ & $\%$ \\
\hline January & -7.4 & 4.7 & 2.4 & 46 & 53 \\
\hline February & -6.2 & 4.7 & 2.5 & 46 & 54 \\
\hline March & -4.1 & 4.6 & 3.2 & 40 & 52 \\
\hline April & 0.1 & 4.6 & 4.1 & 47 & 58 \\
\hline May & 4.4 & 4.3 & 5.7 & 61 & 63 \\
\hline June & 7.8 & 4.3 & 7.3 & 86 & 62 \\
\hline July & 9.7 & 4.4 & 8.3 & 107 & 59 \\
\hline August & 9.1 & 4.3 & 8.1 & 100 & 59 \\
\hline September & 6.9 & 4.0 & 7.1 & 71 & 52 \\
\hline October & 2.8 & 4.0 & 5.1 & 52 & 50 \\
\hline November & -2.6 & 4.0 & 3.5 & 46 & 52 \\
\hline December & -6.2 & 4.4 & 2.7 & 42 & 51 \\
\hline
\end{tabular}



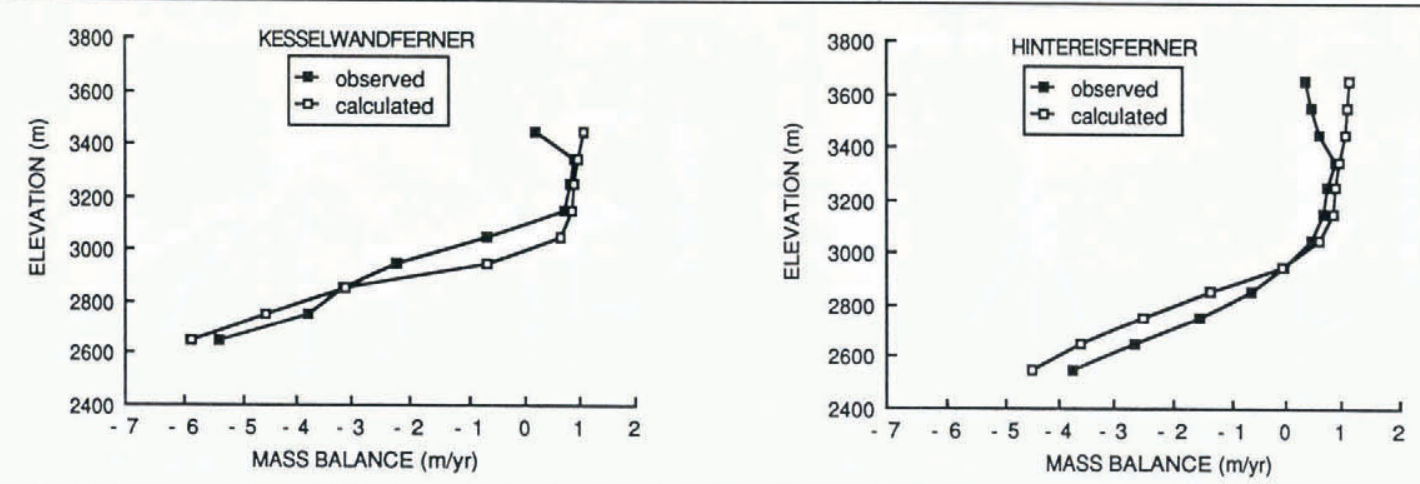

Fig. 4. Mass balance (water equivalent) calculated for Kesselwandferner and Hintereisferner (Oetztal Alps, Austria). The calculations are based on the same meteorological data (from Vent), but take into account differences in exposure, surface slope, and shading.
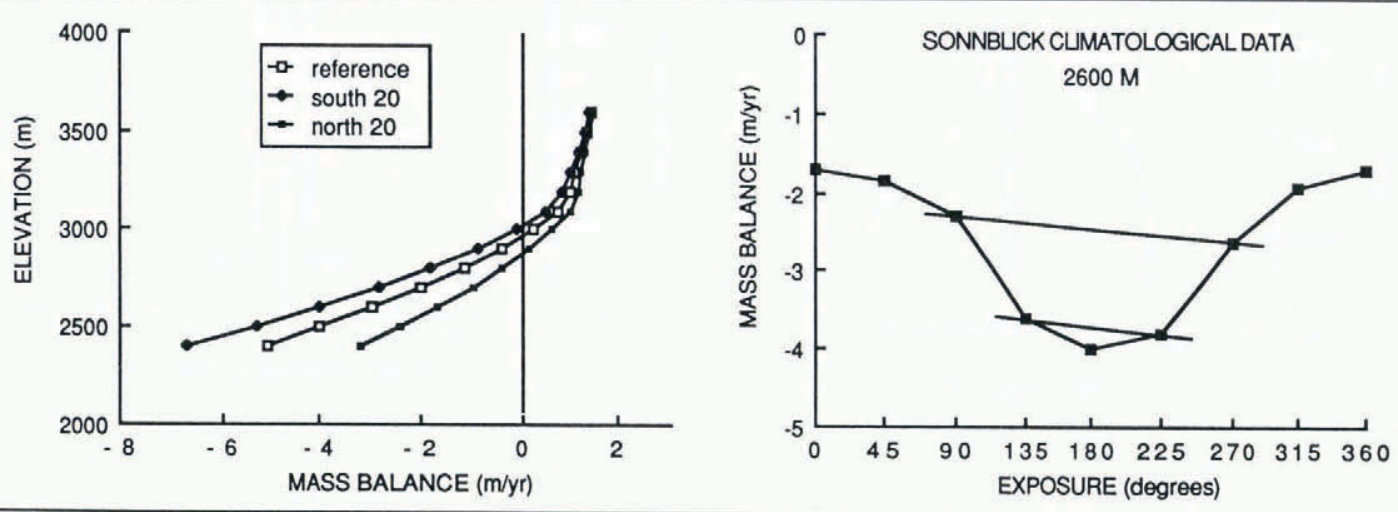

Fig. 5. The Sonnblick mass-balance profile for southerly and northerly exposure (left). Note the large difference in balance gradient in the ablation zone. At the right, the mass balance at a specific elevation $(2600 \mathrm{~m})$ is shown in dependence of exposure. The asymmetry around $180^{\circ}$ is due to a daily cycle in the mean surface albedo.

"recent precipitation history" in the model. In reality, the asymmetry is probably larger, because air temperature in the afternoon is higher in valleys exposed to the south-west. However, this point has not been investigated here.

The sensitivity to shading is relevant for calculating present-day balance profiles, but may also play a role on longer time-scales. An advancing and thickening glacier, for instance, may gradually become subject to different shading conditions. In Figure 6, results are shown for shading angles (elevation of mountain crest relative to a horizontal plane) of $20^{\circ}, 30^{\circ}$, and $40^{\circ}$. Again, the effect is strongly nonlinear, which has to be expected: for low solar elevation the incoming energy on a horizontal plane is small anyway, so limited shading has very little effect on the total melt.

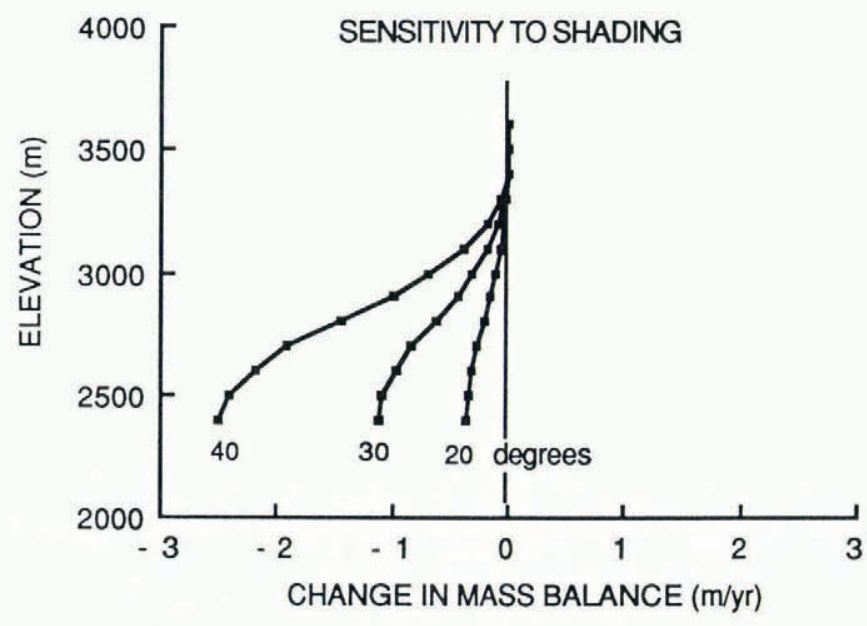

Fig. 6. Effect of shading on the mass-balance profile (Sonnblick climatological data). For a shading angle of le'ss than $10^{\circ}$, the effect is very small.
In our view, the overall performance of the massbalance model gives sufficient confidence to use it for a general study of how sensitive mass-balance profiles are for uniform changes in climatic parameters like mean air temperature, cloudiness, shading, etc.

\section{SENSITIVITY OF MASS-BALANCE PROFILES TO CLIMATIC CHANGE}

We now turn to the central question posed in the beginning of this paper: how do mass-balance gradients react to changes in climatic parameters? A large number of numerical experiments were carried out to investigate this point. Sensitivity has been studied with respect to cloudiness, mean air temperature, precipitation, surface albedo, and mean vapour pressure. The most important results are summarized in Figure 7. A first glance reveals that in most cases the changes in the mass balance decrease with elevation.

When the albedo is high, the effects of cloud on the longwave and shortwave radiation tend to cancel. This explains the small changes in mass balance close to or above the equilibrium line. Down the glacier tongue, however, the shortwave effect dominates and at $2500 \mathrm{~m}$ a uniform (i.e. throughout the year) 0.1 change in cloudiness induces a $0.6 \mathrm{~m} /$ year change in the balance. The influence of decreasing or increasing cloud amount is roughly symmetric with respect to the reference state.

The response to a change in mean air temperature is more complicated. It is highly non-linear and far from symmetric around the reference state. When going down across the equilibrium line, the change in mass balance increases drastically. At high elevation, $3500 \mathrm{~m}$ say, the non-linearity comes out very sharply. In particular, when going from +1 to $+2 \mathrm{~K}$, the decrease in mass balance is dramatic. This large sensitivity is a consequence of the albedo feed-back, and the fact that, apart from large heat fluxes, the ablation season is significantly longer. For lower 


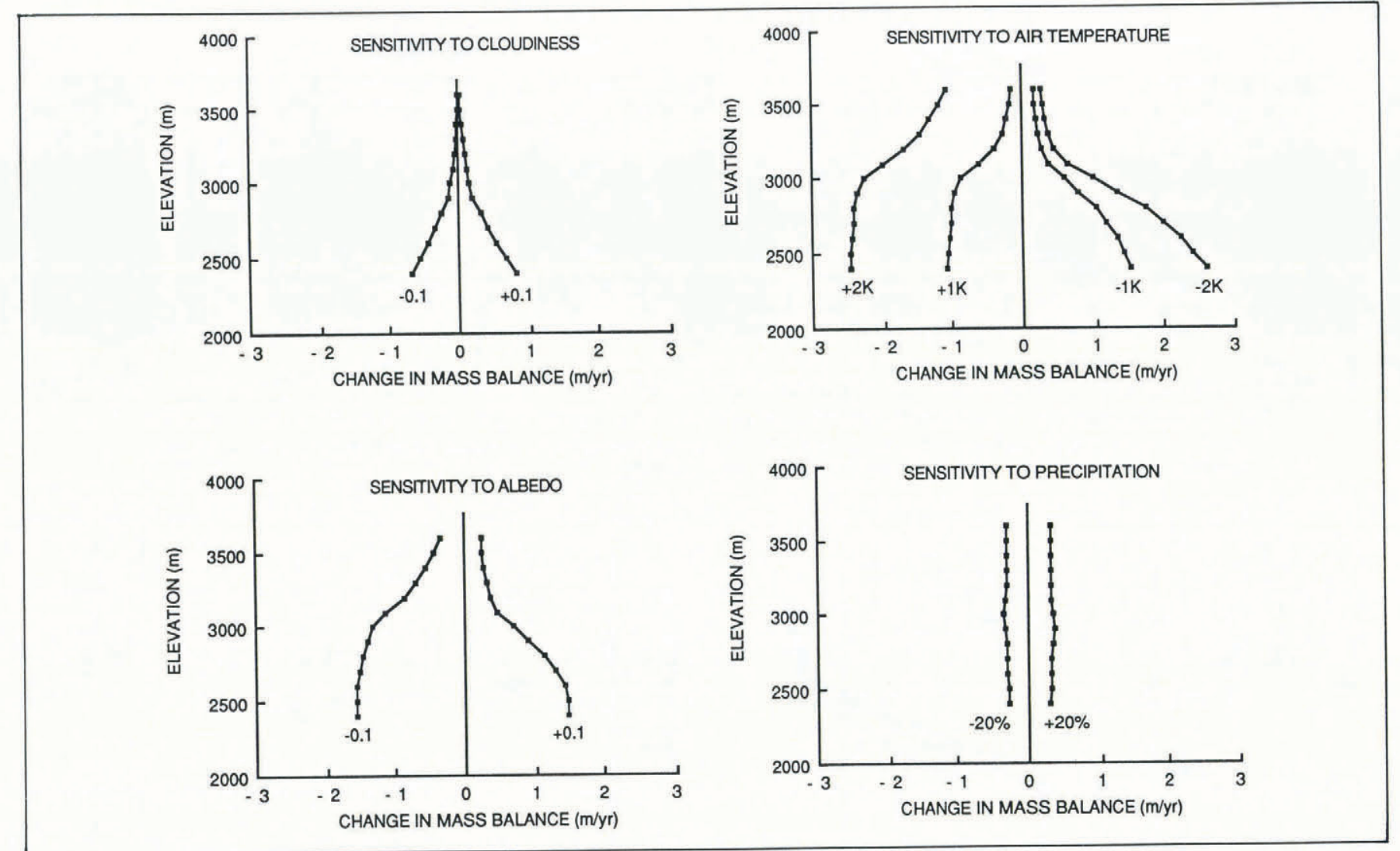

Fig. 7. Sensitivity of Sonnblick mass balance to changes in cloudiness, air temperature, albedo, and precipitation, as indicated by the labels. The imposed changes are constant through the year. Note that the change in mass balance depends strongly on altitude, except for precipitation.

elevation and positive termperature perturbations, the decrease of the mass balance tends to become independent of elevation. For negative temperature perturbations, on the other hand, the positive change in mass balance increases steadily when going downward. These results suggest that the effect of temperature variations depends strongly on the reference situation.

Figure 7 also shows the sensitivity to a uniform change in surface albedo. It illustrates the extreme importance of this quantity. Changes of the order of 0.1 are not very large, and may even indicate the uncertainty in estimates of a mean summer albedo from scarce measurements. This also implies that tuning of a mass-balance model can easily be done by adjusting the parameterization of the albedo.

Results for changes in precipitation are shown in the last panel. It was found that the effect of a $20 \%$ increase in precipitation (uniform through the year!) did not depend strongly on altitude. At the highest elevations, virtually all precipitation falls as snow and the change in mass balance simply equals the change in precipitation. A detailed look into the model output made clear that further down the influence of increased/decreased snowfall starts to affect the albedo in a significant way. The largest changes are found close to the equilibrium line (for a $20 \%$ increase in precipitation this occurs about $100 \mathrm{~m}$ higher than for a $20 \%$ decrease). With decreasing elevation, the fraction of solid precipitation and its effect on the albedo decreases slightly. Still, the overall picture is that a change in precipitation induces a change in mass balance, which is somewhat independent of altitude.

\section{CONCLUSIONS}

The extension of an energy-balance model to a "massbalance model" seems to offer a useful tool to investigate mass-balance profiles, in particular their sensitivity to geometric and environmental factors. It appears that the most critical component in the formulation of the model is the parameterization of the surface albedo, and further work on this is certainly required.
Considering the fact that no tuning was done, the simulation of the balance profiles of Hintereisferner and Kesselwandferner yielded encouraging results. In particular, the difference in melting rates due to differences in surface slope and exposure seems to be well reproduced. Features not treated by the model are reduced accumulation high up in the accumulation zone and the influence of local differences in air temperature and cloudiness (the same climatological data were used for both glaciers).

The dependence of calculated mass balance on slope and exposure appear to be quite reasonable. Unfortunately, it is very difficult to find data which can be used for verification. Mass-balance profiles have been measured on glaciers with various exposures, but then other important factors, like albedo or cloudiness, are unknown. So, here credibility should come from the fact that the model is based on well-established physical concepts!

The most important conclusion of this study concerns the sensitivity to environmental parameters. In fact, the results show clearly that the response of a mass-balance profile to climatic change cannot be expected to be independent of altitude. From this point of view, the application of the "linear balance model" of Lliboutry (1974) to study climatic change cannot be supported. Since, for most environmental parameters, the changes in mass balance tend to decrease with altitude, the equilibrium-line approach, in which the profile is preserved but shifted upward and downward to mimic climatic change, may perform somewhat better. In Table III changes in equilibrium-line altitude $(\Delta E)$ are listed that correspond to the results shown in Figure 7 . Given are the mean values for the positive and negative perturbation experiments. In particular, the sensitivity to air temperature appears to be rather large, which is due to the albedo feed-back in the model. One should, however, realize that there are three contributions involved: turbulent heat flux, longwave radiation from the atmosphere, and fraction of precipitation falling as snow. The fact that these contributions are included in an interactive way makes a comparison with other studies, like the one by Kuhn (1989), difficult. From a detailed linear-perturbation analysis at the equilibrium 
TABLE III. CHANGES IN EQUILIBRIUM-LINE ALTITUDE $(\Delta E)$ DUE TO PERTURBATIONS IN AIR TEMPERATURE, CLOUDINESS, ALBEDO, AND ANNUAL PRECIPITATION
Parameter

$\Delta E$

$\mathrm{m}$

Air temperature, $1 \mathrm{~K}$

131

Cloudiness, 0.1

Albedo, 0.1

Precipitation, 20\% line, based on measurements on Hintereisferner, he found that $\Delta E=65 \mathrm{~m}$ for a $1 \mathrm{~K}$ temperature change. This does include the albedo feed-back, but not the effect of changing incoming longwave radiation. Kuhn suggested that taking this into account would double the value of $\Delta E$, i.e. bring it close to the value found in the present model calculation. The effect of temperature change on solid precipitation cannot be derived from Kuhn's paper, so the comparison cannot be completed.

Many workers have related the equilibrium line to a specific isotherm (annual or summer), implying that the change in the equilibrium-line altitude is given by the temperature change divided by the temperature lapse rate. The present calculation suggests that this procedure probably underestimates changes in equilibrium-line altitude.

As noted at the beginning of this paper, heat storage and superimposed ice are not treated in the present model. The conclusions are for mid-latitude valley glaciers with considerable mass turn-over and, in our view, will not change when these processes are taken into account. For conditions at high latitudes, with a very large seasonal cycle in surface temperature and lower accumulation rates, this is not so obvious. The application of the mass-balance model to (sub)polar ice caps, which is a natural and interesting extension of the present work, in fact requires a much more detailed tratement of surface processes, including run-off. This will be considered in future work.

\section{ACKNOWLEDGEMENT}

I am grateful to M. Kuhn for comments on the first draft of this paper.

\section{REFERENCES}

Dirmhirn, I. and F.D. Eaton, 1975. Some characteristics of the albedo of snow. J. Appl. Meteorol., 14(3), 375-379.

Dirmhirn, I. and E. Trojer. 1955. Albedountersuchungen auf dem Hintereisferner. Arch. Meteorol. Geophys, Bioklimatol., B6(4), 400-416.

Greuell, W. Unpublished. Glaciers and climatic change: energy balance studies and simulation of the historical front variations of the Hintereisferner. (Ph.D. thesis, University of Utrecht, 1989.)

Greuell, W. and J. Oerlemans. 1986. Sensitivity studies with a mass balance model including temperature profile calculations inside the glacier. Z. Gletscherkd. Glazialgeol., 22(2), 101-124.

Günther, R. and D. Widlewski. 1986. Die Korrelation verschiedener Klimaelemente mit dem Massenhaushalt alpiner und skandinavischer Gletscher. Z. Gletscherkd. Glazialgeol., 22(2), 125-147.
Haeberli, W. 1985. Fluctuations of glaciers, 1975-1980. (Vol. IV.) Paris, International Commission on Snow and Ice of the International Association of Hydrological Sciences/UNESCO.

Kasser, P. 1967. Fluctuations of glaciers, 1959-1965. [Vol. 1.] Paris, International Commission on Snow and Ice of the International Association of Hydrological Sciences/ UNESCO.

Kasser, P. 1973. Fluctuations of glaciers, 1965-1970. [Vol. 2.] Paris, International Commission on Snow and Ice of the International Association of Hydrological Sciences/ UNESCO.

Kuhn, M. 1979. On the computation of heat transfer coefficients from energy-balance gradients on a glacier. $J$. Glaciol., 22(87), 263-272.

Kuhn, M. 1981. Climate and glaciers. International Association of Hydrological Sciences Publication 131 (Symposium at Canberra - Sea Level, Ice, and Climatic Change), 3-20.

Kuhn, M. 1984. Mass budget imbalances as criterion for a climatic classification of glaciers. Geogr. Ann., $66 \mathrm{~A}(3)$, 229-238.

Kuhn, M. 1986. Meteorological conditions of mass balance extremes. Materialy Glyatsiologicheskikh Issledovaniy 57, 149-153.

Kuhn, M. 1989. The response of the equilibrium line altitude to climate fluctuations: theory and observations. In Oerlemans, J., ed. Glacier Fluctuations and Climatic Change. Proceedings of the Symposium on Glacier Fluctuations and Climatic Change, held in Amsterdam, 1-5 June 1987. Dordrecht, etc., Kluwer Academic Publishers, 353-371.

Kuhn, M., G. Markl, G. Kaser, U. Nickus, F. Obleitner, and H. Schneider. 1985. Fluctuations of climate and mass balance: different responses of two adjacent glaciers. $Z$. Gletscherkd. Glazialgeol., 21, 409-416.

Letréguilly, A. 1988. Relation between the mass balance of western Canadian mountain glaciers and meteorological data. J. Glaciol., 34(116), 11-18.

Lliboutry, L. 1974. Multivariate statistical analysis of glacier annual balances. J. Glaciol., 13(69), 371-392.

Martin, S. 1978. Analyse et reconstitution de la série des bilans annuels du Glacier de Sarennes, sa relation avec les fluctuations du niveau de trois glaciers du Massif du Mont-Blanc (Bossons, Argentière, Mer de Glace). Z. Gletscherkd. Glazialgeol., 13(1-2), 1977, 127-153.

Meyers, T.P. and R.F. Dale. 1983. Predicting daily insolation with hourly cloud height and coverage. J. Climate Appl. Meteorol., 22, 537-545.

Oerlemans, J. 1989. On the response of valley glaciers to climatic change. In Oerlemans, J., ed. Glacier Fluctuations and Climatic Change. Proceedings of the Symposium on Glacier Fluctuations and Climatic Change, held in Amsterdam, 1-5 June 1987. Dordrecht, etc., Kluwer Academic Publishers, 353-371.

Priestley, C.H.B. 1959. Turbulent transfer in the lower atmosphere. Chicago, IL, University of Chicago Press.

Scheibbner, F. and W. Mahringer. 1968. Die Albedo der Sonnblickgletscher und ihre zeitlichen Variationen. Arch. Meteorol. Geophys. Bioklimatol., B16(2-3), 174-194.

Sellers, W.D. 1965. Physical climatology. Chicago, IL, University of Chicago Press.

Wagner, H.P. 1979. Strahlungshaushaltsuntersuchungen an einem Ostalpengletscher während der Hauptablationsperiode. Teil 1: Kurzwellige Strahlung. Arch. Meteorol. Geophys. Bioklimatol., B27(4), 297-324.

Walraven, R. 1978. Calculating the position of the Sun. Sol. Energy, 20, 393-397. 